\title{
Jingdezhen ceramic "old" brand heritage and redesign
}

\author{
Yuchuan Guo ${ }^{1}$, Yuanyuan Fan ${ }^{2}$ \\ ${ }^{1}$ University of Jingdezhen ceramic art institute of design, China;333403 \\ ${ }^{2}$ Tsinghua university academy of fine arts, China; 100084
}

Keywords: Jingdezhen ceramic, "old", the brand heritage, redesign.

\begin{abstract}
In Jingdezhen ceramic research aspects of the "old", personal or based on their own professional and brand design point of view to study, and puts forward specific solutions, hope that through brand design method on the inheritance and development of Jingdezhen "old" have different attempts, that is why the author research this topic.
\end{abstract}

\section{Introduction}

Domestic currently works in the "old" more, but not for the ceramic "old", and this paper mainly expounds the inheritance and development of the "old". Such as MuJianKang studies of old brand activation in Henan province, this paper puts forward with the change of the market environment and market competition intensifying, old faces severe challenges, some old were retired, gradually aging. Based on the analysis of Henan province, on the basis of general situation and characteristics of old to Henan's time-honoured brand has carried on the thorough analysis, put forward the strategies of the old brand activation in Henan province. The article is also can study from the perspective of brand innovation, but there was no cross major to study from the perspective of brand design to solve the problem., such as Mr Liu snow "for the purpose of brand activation of old store innovation design analyzed how to apply the theory of brand activation in recovery and revitalization of the old brands. According to the old brand activation strategy, analysis and research the innovation of the old store design strategy, namely on the visual image to build the traditional artistic conception, expand the depth and breadth of product types, break through the traditional mode to create diverse service experience. Article has referred to the redesigned stores, but not from the perspective of brand design basis that CI system design thinking. In addition, foreign to the "old" enterprise of related research is less seen in written down, but because of the "old" brand abroad market environment and design aesthetic, unlike China, so their heritage and development and brand design has obvious advantages

\section{Jingdezhen Ceramics Brand Heritage}

"The Chinese to the number of porcelain, porcelain industry peak is the". Jingdezhen is one of the earliest industrial city in the world, in the course of history of many well-known firms. In the republic of China in the late Qing dynasty, for example, such as founded in 8 years of the republic of China (1919) "god bless China porcelain industry company," the shareholders not only vigorously promotes the operation and management, and excellent production technology, increasingly, and make "god bless China" brand, business has become more and more fire, become one of the powder yip "SanDing armour", at the same time, Jiangxi porcelain industry company and Yang Fusheng made porcelain, porcelain that is referred to as cut "SanDing armour". "Rao Huafeng porcelain industry" because of its quality, provincial government chairman Xiong Shihui in Rao home custom table for 10104 head of tableware to Chiang Kai-shek. This batch of porcelain wares to Taiping business exhibition in Nanjing, was a sensation. In 1946 Wang no recipient government ordered after porcelain, round part by Rao Huafeng porcelain factory make grinders. Tao school in 1947 in the second batch of Huomintang in the porcelain to princess Elizabeth of England married with porcelain also by Rao Huafeng porcelain industry are all white. In addition, Jiao QiFeng 
constant vibration, tong Hua Mishan, Tang Yiyuan, far hall, Cui Wei Ge is also at the same time leading firms such as "brand".

After the Maguan treaty, the imperialists to open a lot of porcelain industry in China, and the rulers of destruction and looting, and business management idea conservative, lack of innovation, backward technology, Jingdezhen porcelain industry in trouble, so that the ceramic old dying off. The title of "ceramics capital of China" have made Jingdezhen clueless for hundreds of years, however, in today's era of market economy, Jingdezhen ceramics industry due to not adapt to the market and the change of environment, lack of technological innovation and design, also gradually lost in the ceramic market advantage.

Today, Jingdezhen has cannot see the shadow of the "old" ceramic, instead of many emerging brands. Only a few "old" and continued, "Ian Robinson porcelain" was founded in 1873 (Qing stagnation period), the fourth-generation successor Wen-bo Luo Laurence family and founded the Jingdezhen porcelain ceramics co., LTD., on the basis of inheriting forefathers, one hundred years old and carried forward. Also, the Hui spring ceramics co., LTD., in one hundred, the old "yong and spring", has a good reputation and public praise in the industry, in 2013, "yong and spring" brand won the famous trademark in Jiangxi province.

Some countermeasures: the fact the embarrassment of already very clear, once the gold-lettered signboard of unlimited scenery, the heads of its are fading. Did not reflect the brand value, most of the old, but not large-scale, substantive business operations, from the point of view of the long-term management of brand, brand aging problems, will have to be on the current situation of the "old" census, and extensively collecting and organizing the "old" information. To do the following points:

1 , actively conduct academic research, discover and inheritance of traditional ceramics and excellent skills and business culture, analyses its historical development, business philosophy, product positioning, social influence.

2, the introduction of positive market rule, make accurate product positioning, brand and design bold, maximize the value of the "old".

3 , the in-depth study of the "old" is to guide when

Second, Jingdezhen ceramics "old" design again

Jingdezhen ceramic "old" design. Ceramic "old", not only stay on the basis of the original ceramic products, she always refers to the quality of product of pottery and porcelain, crafts, porcelain, etc are very perfect. So according to the above definition we should enrich the old products, as the demand of the rapid change, people often is not limited to previous CiYi product, aesthetic will occur some changes, so in the moment of Jingdezhen glaze, is also a selection of "old" Jingdezhen ceramics, ceramic glaze species are very abundant, glaze colors, color under the glaze, glaze, such as types, we will design again from the following several aspects.

\section{Glazing Color and Color Materials of the Jingdezhen Ceramics}

Color glaze is also called the glaze, is a class of enamel. A single crystallization glaze, glaze color glaze, glaze, crackle glaze, etc. Color glaze is depend on the change of water color to decorate the porcelain, usually in the adjustment of various trace elements content in the glaze, as the iron, copper, manganese and cobalt metal oxide, after firing, depending on the glaze contains trace elements, producing green, brown, red, blue, etc all kinds of glaze color effect, youligong contains a certain amount of iron, after firing a cyan; Contain a certain amount of copper, after burning red or green. Because some color glaze kiln firing temperature, and oxidizing atmosphere of different produce unexpected effect of kiln. For example, some glaze after firing, the effect of the grain appearance appear abstract connotation of this effect is not only rich products, give a person infinite imaginary space. Thus, color glaze used in ceramic product design, can give a person a surprise, transform the rich shade effect, but also can enrich the surface decoration of ceramic products. (as shown in figure 1 ) 


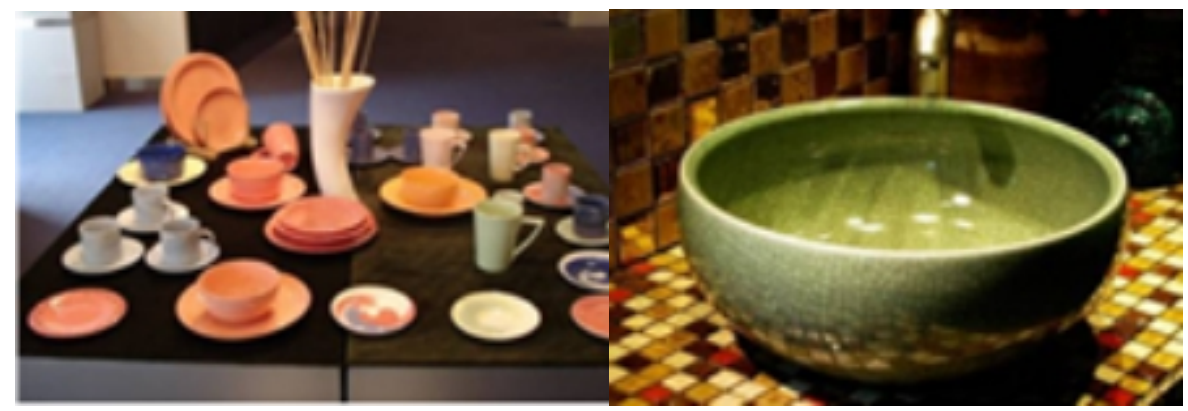

Figure 1 as shown in figure 1 .

Under the glaze color is also called "kiln". Under the glaze color is a major means of decorative ceramics, is coloring materials in the dry grain forming (semi-finished products) to draw on a variety of decorative pattern, and then cover with white transparent glaze or other light color glaze, after completion of drawing into the kiln. Under the glaze color color is blue and white, youligong, black, blue, brown, yellow, green and other colors. (as shown in figure2)

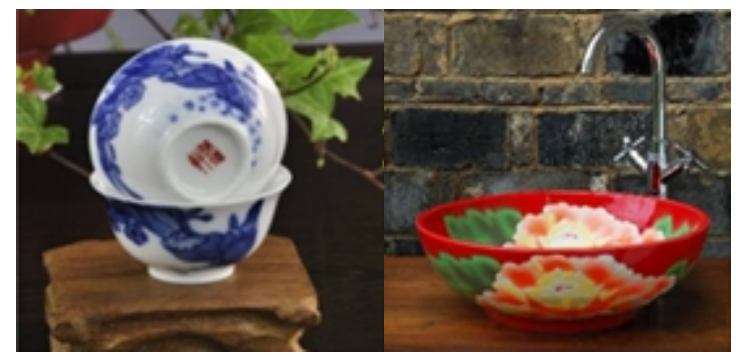

Figure 2 as shown in figure2.

On glaze color, it is need to first fire white glazed porcelain, porcelain or firing glaze porcelain or more color porcelain, conducted on the ceramic coloured drawing or pattern, and then into the kiln by 600 degrees to 600 degrees Celsius temperature baking. Glaze on the variety of color, enamel, enamel color, colorful, color new, etc. The color of each on the glaze color is divided into a lot of kinds, for example, ancient color have big green, bitter green, ancient water green, pale green, aqua green. Ancient emerald green, yellow, violet wait for color. New color have red, purple, cyan, western red, carmine, yellow and other colors. Pastel have hard green, pink green, pink jade, loose powder big green, blackish green, green, green wait for color stones. (as shown in figure3).

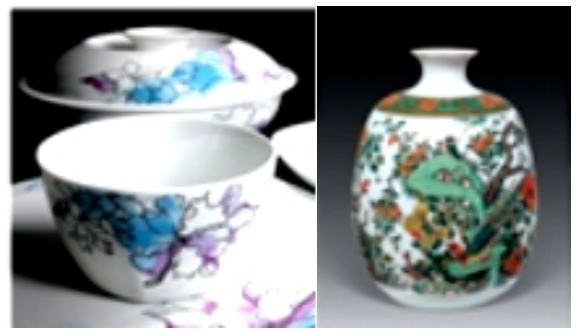

Figure 3 as shown in figure3.

\subsection{The popular colour "old" begin of Jingdezhen ceramics}

Jingdezhen ceramics product design both in shape and too traditional and conservative in color, color changes little, backward kinds of design and color, the shape of a single, lack of innovation, science and technology content is low, poor product quality problems. This is Jingdezhen ceramic products on the market is increasingly difficult. As foreign brands of injection, competition is fierce between ceramic products. Jingdezhen ceramic products to improve the market competitiveness of products, must work in terms of style and colour, Jingdezhen has rich resources of porcelain making, in the ceramic glaze color resources accumulated deep, glaze color diversity, adornment effect is rich and colorful, for the Jingdezhen ceramic product innovation has laid a good foundation. 
The innovation of the Jingdezhen ceramic color should be combined with local glaze color characteristics into fashion colour element. Some foreign experience proved that, using the timely fashion colour, will greatly enhance the added value of products. At this point in countries such as Japan, South Korea, northern ceramic products of embodiment. In these countries designers will apply some popular colour in ceramic design. Such as the use of clothing color, each a new fashion conference, will convey the consumers for the latest color preferences. Designers can get inspiration from the fashion colour is applied, the refinement to the colour element in ceramic products, make its use in the design of the future. So that we can deepen the development of product of pottery and porcelain decoration new direction, and further reflect the rationality of its color, artistic, scientific, give a person with comfortable and aesthetic enjoyment, make ceramic products design design and color, can see the local traditional characters and can feel the charm of popular colour to ceramic products. Thus, the designer of these countries is not satisfied with the country's traditional glaze decoration, but according to the modern aesthetic characteristics and requirements, on the basis of traditional glaze to innovation, make our products more in line with the fashion trends, conform to the consumer's aesthetic orientation, the ancient art in modern production design to shine, very popular. And this method also reflects the inheritance and innovation of the traditional culture. Kill two birds with one stone of it. For example, the design of the figure 4 lavabo, inspiration comes from the World Cup in South Africa, apply the colour, modelling of football and the design of the sink, not only fun, but also has fashion sense.

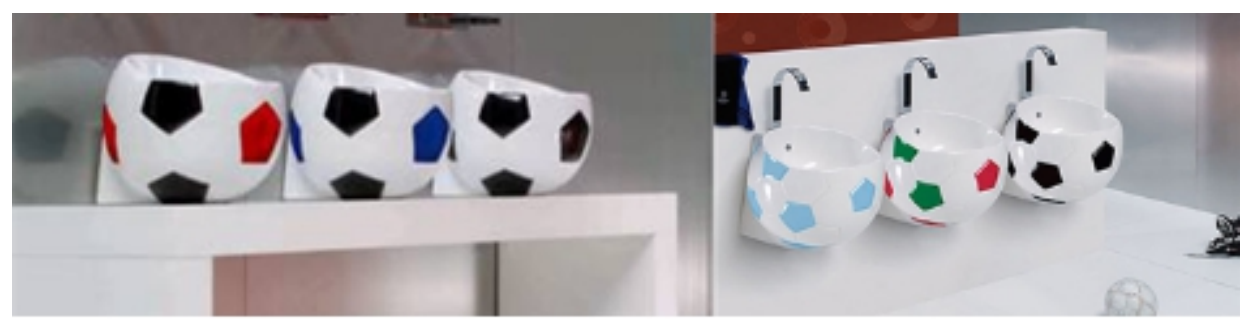

Figure 4 as shown in figure4.

\section{Conclusion}

To sum up, the "old" brand revitalization and development of Jingdezhen ceramics, ceramic old inheritance is not just a person has the obligation to, she is our Jingdezhen ceramics common shoulder the task of each child. And even the sons and daughters of the Chinese nation. Ceramic "old" condenses the national spirit, history and culture and geographical attributes, ceramic art is a miracle of the Chinese civilization, one of the symbol is the cultural content and historical of Jingdezhen city. Jingdezhen ceramic "old" is the main body of intangible assets, industry and commerce is the business for many years successful experience, strength and competitiveness of enterprises, has a very high commercial and cultural value.

\section{Acknowledgments}

Jiangxi Province art science planning topics: Inheritance and brand redesign of "old brand" of Jingdezhen ceramics, YG20150101.

\section{References}

[1] Xiu-mei wu: the inheritance and change - Jingdezhen porcelain development research of the republic of China, Beijing, guangming daily press, 2012.

[2] Xiu-mei wu: the traditional handicraft culture research - ceramic hangzhou fan, for example, Beijing: guangming daily press, 2013.

[3] Zhen-fan wan, Lin Songhua editor: studies of modern times social transformation in jiangxi, Beijing: China social sciences press, 2001. 
[4] XiChuan performance: "the classical works of design art anthology, nanjing: southeast university press, 2002.

[5] Zhou Ronglin, one thousand porcelain rhyme: Jingdezhen ceramic culture expo [M]. Nanchang: jiangxi people's out of the club, 2004.

[6] Zheng Jianqi Hu Fei, art design methodology [M], Beijing: tsinghua university press, 2009.

[7] Shou-zhi wang. The history of modern design [M]. Beijing: China youth publishing house. 2002.

[8] Ji-yao ling. Art design ten five speakers [M]. Beijing: Peking University press. 2006. 